\title{
Females with schizophrenia have abnormal functional cortical connectivity in the gamma frequency during an auditory oddball task using magnetoencephalography
}

\author{
Toshiro Fujimoto $^{{ }^{*}}$, Eiichi Okumura ${ }^{2}$, Kouzou Takeuchi ${ }^{1}$, Atsushi Kodabashi ${ }^{1}$, Toshiaki Otsubo ${ }^{1}$, \\ Katsumi Nakamura $^{1}$, Masaki Sekine ${ }^{3}$, Shinichiro Kamiya ${ }^{3}$, Yuji Higashi ${ }^{1}$, Susumu Shimooki ${ }^{1}$, \\ Toshiyo Tamura ${ }^{3}$ \\ ${ }^{1}$ Fujimoto General Hospital, Fujimoto Medical System, Miyazaki, Japan \\ ${ }^{2}$ Neuroscience Project Office, Yokogawa Electric Corporation, Ishikawa, Japan \\ ${ }^{3}$ Faculty of Biomedical Engineering, Osaka Electro-Communication University, Osaka, Japan \\ Email: ${ }^{*}$ ceo@fujimoto.or.jp
}

Received 6 November 2013; revised 26 November 2013; accepted 4 December 2013

Copyright (C) 2014 Toshiro Fujimoto et al. This is an open access article distributed under the Creative Commons Attribution License, which permits unrestricted use, distribution, and reproduction in any medium, provided the original work is properly cited. In accordance of the Creative Commons Attribution License all Copyrights (C) 2014 are reserved for SCIRP and the owner of the intellectual property Toshiro Fujimoto et al. All Copyright (C) 2014 are guarded by law and by SCIRP as a guardian.

\section{ABSTRACT}

We studied differences in imaginary coherence (IC) of the gamma band between brain regions of female schizophrenia patients during the auditory oddball task using magnetoencephalography (MEG). Subjects were 12 right-handed female schizophrenia patients, who were evaluated by the Positive and Negative Syndrome Scales (PANSS). Functional connectivity during an auditory oddball task was reconstructed in low gamma $(30-50 \mathrm{~Hz})$ and high gamma $(50-100 \mathrm{~Hz}$ and $100-150 \mathrm{~Hz}$ ) bands, and represented by IC using seeds determined by the significant oscillatory power changes obtained by event-related synchronization (ERS) and event-related desynchronization (ERD) power measurements. Gamma ERS (30 - 50 Hz) power was decreased in the left precuneus at 500 $750 \mathrm{~ms}$ and in the right precuneus at $750-1000 \mathrm{~ms}$. IC in the gamma band $(50-100 \mathrm{~Hz})$ was decreased between the right precuneus (seed) and right paracentral lobule (target) and between the right precuneus and right hypothalamus at $0-250 \mathrm{~ms}$. IC in the gamma band $(100-150 \mathrm{~Hz})$ was increased between the left precuneus and right cuneus (Brodmann area 7) at $250-500 \mathrm{~ms}$, between the left precuneus and right culmen at $500-750 \mathrm{~ms}$, and between the left precuneus and right cuneus (Brodmann area 17), between the left precuneus and right posterior cingulate cortex, and between the left precuneus and right caudate nucleus at $750-1000 \mathrm{~ms}$. In the high gamma band $(50-100 \mathrm{~Hz})$ at $0-250 \mathrm{~ms}$, significant positive

*Corresponding author. correlations were shown between IC and conceptual disorganization in PANSS scores, between IC and unusual thought content score, and between IC and positive scale score. IC within the high gamma band in female schizophrenia patients showed two types of functional disconnection, intrahemispheric and interhemispheric. IC between the right or left precuneus and other specific cortical areas showed dysfunction, suggesting that the parietal lobe plays an important role in dysfunction in connectivity in the gamma band during the oddball task.

\section{KEYWORDS}

Schizophrenia; Female; Gamma Band; Coherence; Functional Connectivity Oddball;

Magnetoencephalography

\section{INTRODUCTION}

Advances in magnetoencephalography (MEG) and electroencephalography (EEG) technology have made it possible to obtain noninvasive mapping of changes in large-scale networks during perceptual and higher cognitive processes. Study of event-related potentials (ERP) has revealed that gamma-band synchronization plays an important role in information processing in the networks of neurons in the brain $[1,2]$. Gamma-band synchronization subserves numerous higher cognitive functions, such as visual stimulation [3,4], working memory [5], and awareness and selection [6-12]. The pattern of synchronization flexibly determines the pattern of neuronal inte- 
ractions [13], and may promote the transfer of relevant information between distinct brain systems $[1,14,15]$.

A number of studies have shown abnormalities of gamma-band oscillations and synchrony in schizophrenia patients using EEG and MEG. It has been hypothesized that these abnormalities in the gamma-band reflect neural circuit abnormalities in this disorder [16]. In one study [17], schizophrenia patients had reduced EEG power at $40 \mathrm{~Hz}$, reflecting selective deficits in early stage sensory processing in the auditory networks, which may reflect dysregulation of N-methyl-D-aspartate (NMDA) receptors. In another study [18], synchronous gamma $(40 \mathrm{~Hz})$ activity was decreased overall in frontal areas and the left hemisphere in schizophrenia patients, and schizophrenia syndromes could be differentiated by distinct patterns of gamma disturbances: psychomotor poverty showed decreased left hemisphere synchrony; reality distortion was associated with increased right synchrony; and disorganization showed a widespread enhancement with a delay in frontal synchrony. Chronic schizophrenia patients have been reported to show reduced global functional connectivity in lower gamma phase synchrony [19]. First-episode schizophrenia patients showed a decreased magnitude and delayed latency for global early gamma ( $-150 \mathrm{~ms}$ to $150 \mathrm{~ms}$ post stimulus) in a conventional auditory oddball task [20]. Schizophrenic patients who had specific frequency deficits in the generation and maintenance of coherent gamma-range oscillations underwent auditory steady state event-related potential testing, where the stimulus-driven activity may reflect the capacity for integrated, bottom-up activity of auditory sensory network processing [21]. Abnormal oscillations and synchrony in beta and gamma bands in schizophrenia suggested selective deficiencies in the ability of cortical networks or cortico-thalamo-cortical loops to engage in precisely synchronized high frequency oscillations [22-25]. Phase locking factor and evoked power were decreased at fronto-central electrodes during $40 \mathrm{~Hz}$ auditory steady-state responses in schizophrenic patients, suggesting the possibility of differential neural circuit abnormalities in the left and right auditory cortices [26]. Although function and generating mechanisms are unclear in the high gamma band $(60-200 \mathrm{~Hz})$, it has been suggested that the high gamma band is impaired in schizophrenia [27]. High gamma band activity $(60-200 \mathrm{~Hz})$ is thought to have an important role for cortical computation through establishing correlation between the modulation of high gamma oscillations and specific cognitive functions, and impairment of high gamma activity has been reported in neuropsychiatric disorders such as schizophrenia [27]. Cross-frequency coupling between the high- and low-frequency bands of ongoing electrical activity modulates power in the high gamma (80 - 150 $\mathrm{Hz}$ ) band and provides a mechanism for effective com- munication during cognitive processing [28-31]. Impairments in the high gamma band in schizophrenia have been linked to dysfunction in cross-frequency coupling [2]. Impairments in long-range synchronization in schizophrenia are probably related to changes in white matter volume and organization, because long distance synchronization of oscillatory responses is thought to be mediated by reciprocal cortico-cortical connections [2].

The coherence hypothesis states that neuronal communication is mechanistically subserved by neuronal coherence, and activated neuronal groups oscillate and thereby undergo rhythmic excitability fluctuations that produce temporal windows for communication [32]. Synchronized firing between cells in different functional columns has been associated with rhythmic discharge in the gamma band $(20-70 \mathrm{~Hz})$, suggesting a functional link between gamma oscillations and response synchronization $[4,6,7,33]$. In this study we calculated coherence as imaginary coherence (IC) to find functional connectivity in the gamma band between different brain regions.

A number of reports have demonstrated gender differences in ERP studies [34] found significant gender differences in the event-related field (ERF) pattern in semantic encoding of study words and interpreted this as an effect of sex-related hemispheric asymmetry. In studies of auditory processing, M100 sources in males were significantly more anterior on the superior temporal gyri than those in females, suggesting greater hemispheric lateralization in males compared to females [35]. We previously demonstrated gender-related differences in the gamma band, and reported increased activities in the left prefrontal and the right midline parietal, and decreased activities in males in the gamma band, compared to females. Near-infrared spectroscopy (NIRS) data in the visual and auditory task showed that males displayed a higher percentage of oxygen saturation of hemoglobin $\left(\% \mathrm{StO}_{2}\right)$ in frontal brain areas; males also showed a higher increase in $\% \mathrm{StO}_{2}$ [36]. Gender differences in functional connectivity were also reported in gamma phase synchrony; female schizophrenia patients had more reduction in global functional connectivity than male patients, suggesting that additional breakdown in brain network connectivity may develop with illness chronicity in female patients [19,37]. It is therefore prudent to separately examine female and male groups of psychiatric patients. We examined female schizophrenia patients in this study.

We examined IC in the gamma band between a seed and target points to study functional connectivity during the conventional auditory oddball task [38]. First, we obtained event-related synchronization (ERS) and eventrelated desynchronization (ERD) in the gamma band (30 - $50 \mathrm{~Hz}, 50-100 \mathrm{~Hz}$ and $100-150 \mathrm{~Hz}$ ) in order to acquire a seed of IC. High gamma ERS has exhibited func- 
tional response properties that have distinguished it from ERD/ERS phenomena [39-45]. Next, we obtained IC between brain regions. We have previously reported dysfunction in functional connectivity in low gamma (30 - $50 \mathrm{~Hz})$ and high gamma $(50-100 \mathrm{~Hz})$ bands in male schizophrenia patients during the auditory oddball task, using the same methods of IC analysis as in this study. We found decreased IC between certain areas and correlations, between decreased IC and PANSS scores, suggesting that functional disconnection in gamma bands may play an important role in the auditory processing of male patients with schizophrenia [38]. The purpose of this study is to investigate changes in functional connectivity in the gamma band in female schizophrenia patients.

\section{METHODS AND MATERIALS}

\subsection{Participants}

Twelve right-handed female patients with schizophrenia (mean age, $30.9 \pm 5.2$ years) were examined (Table 1(a)). The patients were diagnosed according to DSM-IV-TR criteria (American Psychiatric Association, 2000); five were inpatients and five were outpatients who had been medicated with neuroleptics for 2 - 15 years. Their overall psychopathology was evaluated by the Positive and Negative Syndrome Scale for schizophrenia (PANSS) [46]. We tested for associations between coherence in the gamma band and PANSS score using correlation analysis. All patients were screened by medical history, laboratory testing, and Magnetic Resonance Imaging (MRI) or CT. Twelve healthy, right-handed female volunteers (mean age, $28.6 \pm 5.4$ ) without psychiatric illness were used as controls (Table 1(b)). There were no significant differences in mean age between the patient and control groups. All subjects gave written informed consent after receiving oral and written explanations of the nature of the study.

\subsection{Standard Auditory Oddlball Paradigm}

The standard auditory oddball paradigm was performed with a stimulus sequence in which the target tone was $2000 \mathrm{~Hz}$ with a probability of $20 \%$ and the non-target tone was $1000 \mathrm{~Hz}$ with a probability of $80 \%$ [38]. Both stimuli were delivered binaurally by a sound stimulator for a duration of $100 \mathrm{~ms}$, rise/fall time of $10 \mathrm{~ms}$, intensity of $80 \mathrm{~dB}$ SPL, and constant inter-stimulus interval (ISI) of $2.3 \mathrm{~s}$. Subjects were asked to silently count the number of target stimuli. Three sessions were recorded, each consisting of about 20 target stimuli. Short breaks were given to the subjects between sessions, but head movement was not allowed during breaks. All subjects detected more than $90 \%$ of the stimuli.

\subsection{MEG Recording}

MEG data were recorded in a magnetically shielded room at Fujimoto General Hospital using a 160-channel whole-head MEG system (Yokogawa Electric Corporation, Kanazawa, Japan). The sensing coils in this system are $15.5 \mathrm{~mm}$ in diameter, with a $50-\mathrm{mm}$ baseline and 23-mm separation between each pair of sensing coils. The subjects lay in a supine position with their eyes closed. MEG data were recorded through a $0.16-200 \mathrm{~Hz}$ band-pass filter with a sampling rate of $1000 \mathrm{~Hz}$. In order to confirm P300 activities, we also recorded the EEG using the international 10 - 20 system for electrode placement.

\subsection{Localization of Oscillatory Power Changes}

To localize the ERD/ERS of low-gamma $(30-50 \mathrm{~Hz})$ and high-gamma $(50-100 \mathrm{~Hz}$ and $100-150 \mathrm{~Hz})$ bands, oscillatory power changes in the current density between the active and baseline periods were calculated with 7-mm grid spacing by means of an adaptive spatial filtering [47-50] using a single spherical volume conductor model based on the individual MRI. The baseline period was defined as the time between 250 and $0 \mathrm{~ms}$ before stimulus onset, and the active periods of interest were defined as continuously moving 250-ms windows from stimulus onset to $1000 \mathrm{~ms}$ after stimulus onset. The significance of oscillatory power changes across subjects was tested with Statistical Non-Parametric Mapping (SnPM) (http://www.sph.umich.edu/ni-stat/SnPM/). The functional images were normalized to template brain images created by the Montreal Neurological Institute (MNI) template in SPM8, and a paired t-test between groups (men and women) corresponding to target stimuli was performed using a nonparametric pseudo-t statistic incorporating variance smoothing with a Gaussian kernel (full width at half maximum) of $20 \mathrm{~mm}$. Voxels with differences at $\mathrm{p}<0.05$ (FWE) were considered statistically significant. Three-dimensional images were made on the MNI template brain using MRIcroGL

(http://www.cabiatl.com/mricrogl/), and visualized as lateral (R-LAT and L-LAT), superior (SUP), anterior (ANT), posterior (POST), and medial (R-MED and L-MED) images. We used BrainMap GingerALE Version 2.1 software to transform from MNI coordinate to Talairach coordinate system and from Talairach coordinates to Brodmann areas. The Talairach software, generally known as Talairach Daemon, was created and developed by Jack Lancaster and Peter Fox at the Research Imaging Institute of the University of Texas Health Science Center San Antonio (UTHSCSA). The voxels which had a significant ERD or ERS were adopted as seed (reference) points for functional connectivity analysis described in the next section. 
Table 1. (a) Demographic and clinical characteristics of female subjects with schizophrenia and results of auditory oddball task in MEG and EEG; (b) Demographic characteristics of female control subjects and results of auditory oddball task in MEG and EEG.

(a)

\begin{tabular}{|c|c|c|c|c|c|c|c|c|c|c|c|c|c|c|}
\hline & & & $\simeq$ & & & & & ANS & & & P300 & MEG & EEG & \\
\hline & Age & Handedness & $\begin{array}{l}n_{1} \\
z_{1} \\
\sum_{\infty}^{\infty} \\
0\end{array}$ & 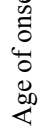 & $\begin{array}{l}\text { Period } \\
\text { of } \\
\text { disease }\end{array}$ & $\begin{array}{l}\text { Number of } \\
\text { admissions }\end{array}$ & 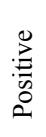 & 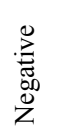 & G & $\begin{array}{l}\text { Correct } \\
\text { answer } \\
\text { rate }\end{array}$ & $\begin{array}{l}\text { Time } \\
(\mathrm{ms})\end{array}$ & $\begin{array}{l}\text { amp } \\
\text { (fT) }\end{array}$ & $\begin{array}{c}\mathrm{amp} \\
(\mathrm{mV})\end{array}$ & Medication \\
\hline 1 & 37 & $\mathrm{R}$ & 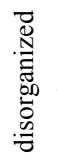 & 32 & 6 & 3 & 18 & 33 & 47 & $92.2 \%$ & 360 & 394.23 & -0.112 & $\begin{array}{l}\text { Haloperidol } 3 \mathrm{mg} \text {; biperiden } 1 \mathrm{mg} \text {; } \\
\text { flunitrazepam } 2 \mathrm{mg} \text {; } \\
\text { quazepam } 15 \mathrm{mg} \text {; clonazepam } 0.5 \mathrm{mg}\end{array}$ \\
\hline 2 & 35 & $\mathrm{R}$ & 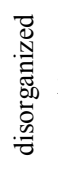 & 26 & 10 & 2 & 15 & 27 & 39 & $100.0 \%$ & 364 & 143.23 & -0.012 & $\begin{array}{l}\text { Risperidone } 7.5 \mathrm{mg} ; \\
\text { zopiclone } 7.5 \mathrm{mg} ; \\
\text { levomepromazine } 25 \mathrm{mg} \\
\text { flunitrazepam } 2 \mathrm{mg} ; \\
\text { quazepam } 30 \mathrm{mg}\end{array}$ \\
\hline 3 & 28 & $\mathrm{R}$ & 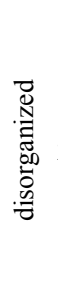 & 24 & 4 & 2 & 24 & 28 & 67 & $100.0 \%$ & 458 & 213.66 & -0.129 & $\begin{array}{l}\text { Perospirone hydrochloride hydrate } 8 \mathrm{mg} \text {; } \\
\text { Levomepromazine } 50 \mathrm{mg} \text {; bromazepam } 5 \mathrm{mg} \text {, } \\
\text { biperiden } 1 \mathrm{mg} \text {; vegetamin }{ }^{\mathbb{B}}-\mathrm{A} \\
\text { (chlorpromazine hydrochloride } 25 \mathrm{mg}, \\
\text { promethazine hydrochloride } 12.5 \mathrm{mg}, \\
\text { Phenobarbital } 40 \mathrm{mg} \text { ); } \\
\text { trihexyphenidyl hydrochloride } 2 \mathrm{mg}, \\
\text { levomepromazine } 25 \mathrm{mg}, \\
\text { sodium valproate } 100 \mathrm{mg}\end{array}$ \\
\hline 4 & 35 & $\mathrm{R}$ & 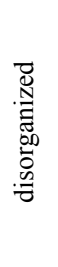 & 19 & 17 & 2 & 27 & 35 & 75 & $83.7 \%$ & 376 & 275.83 & -0.083 & $\begin{array}{c}\text { Perospirone hydrochloride hydrate } 8 \mathrm{mg} \text {; } \\
\text { levomepromazine } 25 \mathrm{mg} \text {, bromazepam } 5 \mathrm{mg} \text {; } \\
\text { biperiden } 1 \mathrm{mg} \text {; vegetamin }{ }^{\mathrm{B}}-\mathrm{A} \\
\text { (chlorpromazine hydrochloride } 25 \mathrm{mg} \\
\text { promethazine hydrochloride } 12.5 \mathrm{mg} \text {, } \\
\text { Phenobarbital } 40 \mathrm{mg} \text { ); flunitrazepam } 2 \mathrm{mg} \text {; } \\
\text { brotizolam } 0.25 \mathrm{mg} \text {; quazepam } 15 \mathrm{mg} \text {; } \\
\text { phenytoin } 100 \mathrm{mg}\end{array}$ \\
\hline 5 & 22 & $\mathrm{R}$ & 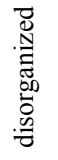 & 18 & 4 & 1 & 15 & 21 & 33 & $98.5 \%$ & 334 & 257.81 & -0.322 & Olanzapine $5 \mathrm{mg}$ \\
\hline 6 & 27 & $\mathrm{R}$ & 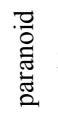 & 25 & 2 & 1 & 18 & 20 & 27 & $92.2 \%$ & 350 & 180.29 & -0.316 & $\begin{array}{l}\text { Risperidone } 2 \mathrm{mg} \text {; biperiden } 1 \mathrm{mg} \text {; } \\
\text { levomepromazine } 25 \mathrm{mg} \text {; } \\
\text { Flunitrazepam } 2 \mathrm{mg} \text {; nitrazepam } 5 \mathrm{mg}\end{array}$ \\
\hline 7 & 34 & $\mathrm{R}$ & 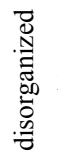 & 20 & 15 & 1 & 20 & 28 & 52 & $95.9 \%$ & 333 & 396.63 & -0.140 & Risperidone $7.5 \mathrm{mg}$; biperiden $1 \mathrm{mg}$ \\
\hline 8 & 32 & $\mathrm{R}$ & 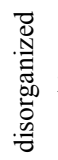 & 22 & 10 & 1 & 20 & 25 & 37 & $100.0 \%$ & 275 & 138.46 & -0.139 & $\begin{array}{l}\text { Etizolam } 0.5 \mathrm{mg} \text {; biperiden } 1 \mathrm{mg} \text {; } \\
\text { risperidone } 2 \mathrm{mg} \text {; zopiclone } 7.5 \mathrm{mg} \text {; } \\
\text { aripiprazole } 6 \mathrm{mg}\end{array}$ \\
\hline 9 & 34 & $\mathrm{R}$ & 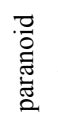 & 31 & 3 & 0 & 11 & 19 & 26 & $100.0 \%$ & 328 & 243.46 & -0.143 & Olanzapine $10 \mathrm{mg}$ \\
\hline
\end{tabular}


Continued

\begin{tabular}{|c|c|c|c|c|c|c|c|c|c|c|c|c|c|c|}
\hline 10 & 25 & $\mathrm{R}$ & 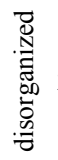 & 25 & 0 & 1 & 21 & 29 & 42 & $86.8 \%$ & 543 & 150 & -0.054 & $\begin{array}{l}\text { Quazepam } 15 \mathrm{mg} \text {; tradospirone } \\
\text { citrate } 10 \mathrm{mg} \text {; olanzapine }(5 \mathrm{mg}+10 \mathrm{mg})\end{array}$ \\
\hline 11 & 37 & $\mathrm{R}$ & 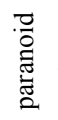 & 36 & 1 & 1 & 11 & 23 & 40 & $96.9 \%$ & 329 & 147.45 & -0.311 & Olanzapine $10 \mathrm{mg}$; olanzapine $5 \mathrm{mg}$ \\
\hline 12 & 25 & $\mathrm{R}$ & 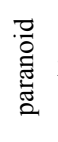 & 24 & 1 & 1 & 13 & 21 & 35 & $98.6 \%$ & 288 & 167.89 & -0.288 & $\begin{array}{c}\text { Aripiprazole } 12 \mathrm{mg} \text {; risperidone } 6 \mathrm{mg} \text {; } \\
\text { blonanserin } 2 \mathrm{mg} \text {; lorazepam } 1.0 \mathrm{mg} * 3 \text {; } \\
\text { levomepromazine } 25 \mathrm{mg} \text {; flunitrazepam } 2 \mathrm{mg} \text {; } \\
\text { zopiclone } 7.5 \mathrm{mg} * 5\end{array}$ \\
\hline Mean & 30.9 & & & 25.2 & 6.1 & 1.3 & 17.8 & 25.8 & 43.3 & $95.4 \%$ & 361.5 & 225.7 & -0.171 & \\
\hline SD & 5.2 & & & 5.4 & 5.5 & 0.8 & 5.0 & 5.2 & 15.0 & $5.6 \%$ & 73.4 & 92.1 & 0.1 & \\
\hline
\end{tabular}

(b)

\begin{tabular}{|c|c|c|c|c|c|c|}
\hline & \multirow{2}{*}{ Age } & \multirow{2}{*}{ Handedness } & \multirow{2}{*}{ Correct answer rate } & P300 & MEG & EEG \\
\hline & & & & Time (ms) & $\operatorname{amp}(\mathrm{fT})$ & amp (mV) \\
\hline 1 & 38 & $\mathrm{R}$ & $98.2 \%$ & 342 & 365.18 & -0.334 \\
\hline 2 & 22 & $\mathrm{R}$ & $98.2 \%$ & 351 & 250 & -0.220 \\
\hline 3 & 28 & $\mathrm{R}$ & $98.3 \%$ & 320 & 238.22 & -0.150 \\
\hline 4 & 25 & $\mathrm{R}$ & $96.5 \%$ & 375 & 119.37 & -0.103 \\
\hline 5 & 27 & $\mathrm{R}$ & $95.9 \%$ & 287 & 231.68 & -0.155 \\
\hline 6 & 25 & $\mathrm{R}$ & $97.0 \%$ & 367 & 219.9 & -0.217 \\
\hline 7 & 31 & $\mathrm{R}$ & $98.5 \%$ & 319 & 184.55 & -0.243 \\
\hline 8 & 28 & $\mathrm{R}$ & $98.5 \%$ & 369 & 259.16 & -0.193 \\
\hline 9 & 33 & $\mathrm{R}$ & $95.6 \%$ & 298 & 268.78 & -0.181 \\
\hline 10 & 28 & $\mathrm{R}$ & $98.5 \%$ & 363 & 314.14 & -0.260 \\
\hline 11 & 37 & $\mathrm{R}$ & $100.0 \%$ & 279 & 332.82 & -0.392 \\
\hline 12 & 21 & $\mathrm{R}$ & $98.3 \%$ & 366 & 200.75 & -0.286 \\
\hline Mean & 28.6 & & $97.8 \%$ & 336.3 & 248.713 & -0.228 \\
\hline $\mathrm{SD}$ & 5.4 & & 0.01 & 34.5 & 67.292 & 0.082 \\
\hline
\end{tabular}

Abbreviation: amp (fT): amplitude of P300 in MEG; amp (mV): amplitude of P300 in EEG.

\subsection{Functional Connectivity Analysis}

After we acquired areas with an abnormal ERD/ERS ratio on the ERD and ERS power map, we used these abnormal regions as seed points for IC (Figure 1). Next, target points were manually searched on the basis of the seed point, and IC between the seed and target points was calculated. As a measure of functional connectivity, we adopted IC to remove the spurious coherence caused by leakage associated with our imaging algorithm $[51,52]$. IC is sensitive to only the synchronizations of two processes that are time-lagged to each other. IC was calculated using seeds (reference points) based on the group analysis results in which oscillatory power changes were observed [38]. The active periods of interest were defined as the continuously moving 500-ms windows from stimulus onset to $1250 \mathrm{~ms}$ after stimulus onset. For source reconstruction, we used the same adaptive spatial filtering and voxel spacing as for localization of oscillatory power changes. We used a short-time Fourier transform with a Hanning window for spectral estimation. Group analysis was performed using the same procedure as localization of oscillatory power changes.

\section{RESULTS}

\subsection{Oscillatory Power Changes}

Female patients with schizophrenia showed differences in ERS power in the gamma band $(30-50 \mathrm{~Hz})$ compared to normal female controls at an FWE corrected $p<0.01$ significance level, using a SnPM paired test during the auditory oddball task (Table 2, Figure 1). Patients 

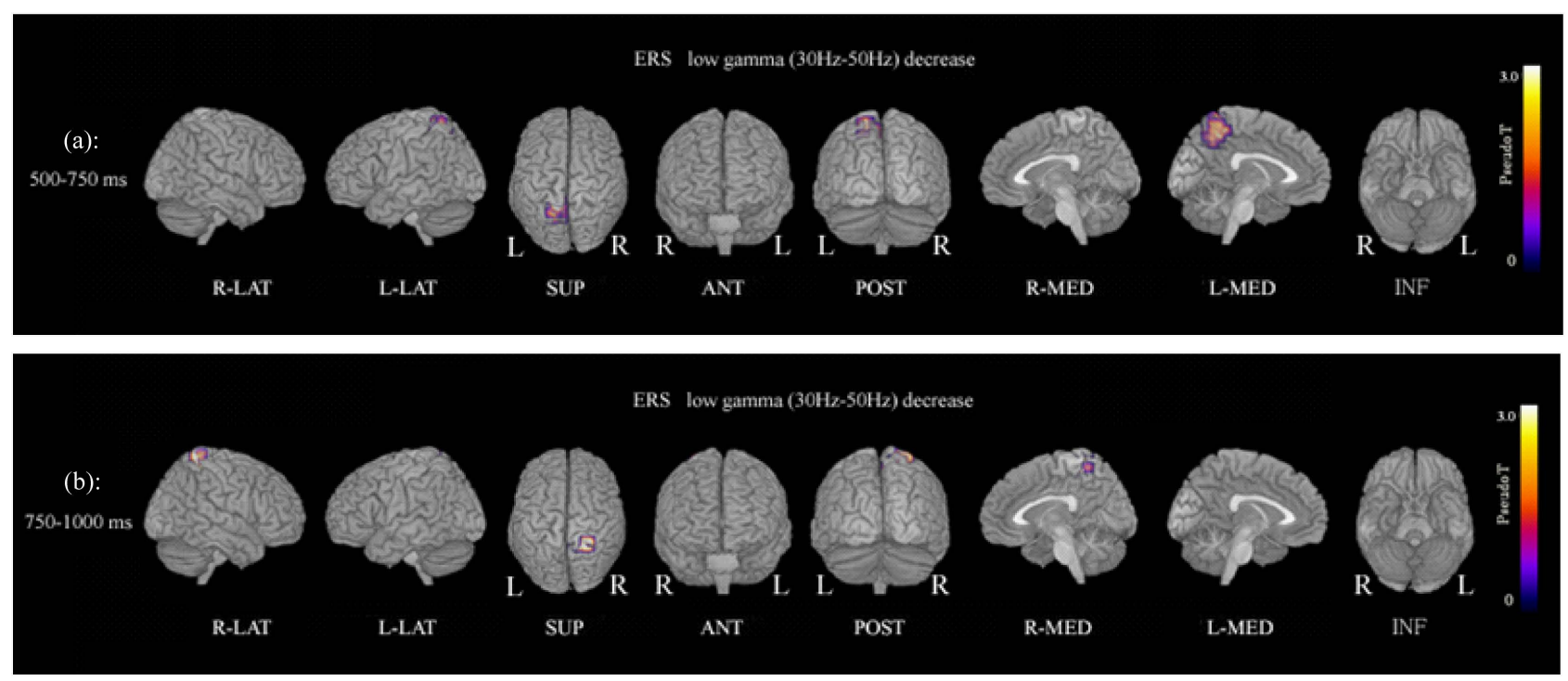

Figure 1. (a) Functional maps of ERS power show statistical differences between patients and controls during the oddball task. ERS power in the low gamma band $(30-50 \mathrm{~Hz})$ at $500-750 \mathrm{~ms}$ was significantly decreased in the left precuneus (Brodemann area 7). p $<$ 0.01 (FWE). Abbreviation: R-LAT: right lateral surface; L-LAT: left lateral surface; SUP: superior surface; ANT: anterior surface; POST: posterior surface; R-MED: right medial surface; L-MED: left medial surface; INF: inferior surface. (b) ERS power in the low gamma band $(30-50 \mathrm{~Hz})$ at $750-1000 \mathrm{~ms}$ was significantly decreased in the right precuneus (Brodemann area 7). $\mathrm{p}<0.01(\mathrm{FWE})$.

Table 2. ERS power showing significant differences between patients and controls during the auditory oddball task.

\begin{tabular}{|c|c|c|c|c|c|c|c|c|c|c|c|c|c|}
\hline & \multirow{2}{*}{ Frequency } & \multirow{2}{*}{ Time window } & \multirow{2}{*}{$X$} & \multirow{2}{*}{$\mathrm{Y}$} & \multirow{2}{*}{ Z } & \multicolumn{2}{|c|}{ Patients } & \multicolumn{2}{|c|}{ Controls } & \multirow{2}{*}{ Pseudo-t } & \multirow{2}{*}{$\mathrm{p}$ (FWE) } & \multirow{2}{*}{ Region } & \multirow{2}{*}{ Brodmann area } \\
\hline & & & & & & Mean & $\mathrm{SD}$ & Mean & $\mathrm{SD}$ & & & & \\
\hline \multirow{2}{*}{ ERS } & $30-50 \mathrm{~Hz}$ & $500-750 \mathrm{~ms}$ & -15 & -56 & 55 & 0.08 & 0.073 & 0.469 & 0.318 & 4.95 & 0.0007 & Precuneus & Brodmann area 7 \\
\hline & $30-50 \mathrm{~Hz}$ & $750-1000 \mathrm{~ms}$ & 20 & -42 & 62 & 0.214 & 0.14 & 0.644 & 0.276 & 5.02 & 0.0005 & Precuneus & Brodmann area 7 \\
\hline
\end{tabular}

BrainMap GingerALE Version 2.1 software was used to transform from MNI coordinates to the Talairach coordinate system and from Talairach coordinates to Brodmann areas. The Talairach software was created and developed by Jack Lancaster and Peter Fox at the Research Imaging Institute of the University of Texas Health Science Center San Antonio (UTHSCSA).

showed decreased gamma ERS power in the left precuneus (Brodmann area 7) at $500-750 \mathrm{~ms}$, and in the right precuneus (Brodmann area 7) at $750-1000 \mathrm{~ms}$ (Figure 1; Table 2). ERD power maps in gamma bands showed no significant differences between patients and control subjects.

\subsection{Functional Connectivity}

IC between seeds and targets was significantly different between patient and control females during the auditory oddball task (FWE: $p<0.05$ ) (Table 3, Figure 2). There was decreased IC in the gamma band $(50-100 \mathrm{~Hz})$ between the right precuneus (Brodmann area 7) (seed) and the right paracentral lobule (Brodmann area 5) (target) and the hypothalamus (target) within the time window 0 - $250 \mathrm{~ms}$. Increased IC in gamma band $(100-150 \mathrm{~Hz})$ was found between the left precuneus (seed) and the right cuneus (Brodmann area 7) (target) at $250-500 \mathrm{~ms}$, and between the left precuneus (seed) and the right culmen (anterior cerebellar lobe) (target) at $500-750 \mathrm{~ms}$. Finally, at 750 - $1000 \mathrm{~ms}$, increased IC was observed between the left precuneus (seed) and the right cuneus (Brodmann area 17) (target), between the left precuneus (seed) and the posterior cingulate cortex (PCC) (Brodmann area 23) (target), and between the left precuneus (seed) and the right head of the caudate nucleus (target).

\subsection{Correlation between IC and PANSS Scores}

Significant correlations between PANSS scores and IC in the high gamma band $(50-100 \mathrm{~Hz})$ were shown between the right precuneus and right hypothalamus areas during the auditory oddball task. These significant positive correlations were between conceptual disorganization in PANSS scores and IC $(r=0.746, p=0.005)$ (Figure 3(b)), between unusual thought content in PANSS scores and IC $(r=0.746, p=0.005)$ (Figure $3(\mathrm{c})$ ), and between the positive symptoms scale in PANSS and IC $(\mathrm{r}=0.728$, $\mathrm{p}=0.007)$ (Figure 3(d)).

\section{DISCUSSION}

IC dysfunction in female schizophrenia patients involved two types of neural connectivity dysfunction: with- 
Table 3. Coordinates of seeds and targets.

\begin{tabular}{|c|c|c|c|c|c|c|c|c|c|c|c|c|c|c|c|}
\hline \multicolumn{3}{|c|}{ Seed } & \multicolumn{13}{|c|}{ Target } \\
\hline \multirow{2}{*}{$\mathrm{X}$} & \multirow{2}{*}{ Y } & \multirow{2}{*}{$\mathrm{Z}$} & \multirow{2}{*}{ Frequency } & \multirow{2}{*}{ Time window } & \multirow{2}{*}{$X$} & \multirow{2}{*}{ Y } & \multirow{2}{*}{$\mathrm{Z}$} & \multicolumn{2}{|c|}{ Patients } & \multicolumn{2}{|c|}{ Controls } & \multirow{2}{*}{ Pseudo-t } & \multirow{2}{*}{$\mathrm{p}(\mathrm{FWE})$} & \multirow{2}{*}{ Region } & \multirow{2}{*}{ Brodmann area } \\
\hline & & & & & & & & Mean & SD & Mean & SD & & & & \\
\hline 20 & -42 & 62 & $50-100 \mathrm{~Hz}$ & $0-250 \mathrm{~ms}$ & 2 & -27 & 55 & 0.089 & 0.047 & 0.165 & 0.059 & 4.83 & 0.0059 & $\begin{array}{l}\text { Right paracentral } \\
\text { lobule }\end{array}$ & Brodmann area 5 \\
\hline \multicolumn{3}{|c|}{ (Right precuneus) } & & & 7 & -2 & -15 & 0.096 & 0.028 & 0.142 & 0.069 & 4.46 & 0.0105 & Right hypothalamus & Hypothalamus \\
\hline \multirow[b]{2}{*}{-15} & & & $100-150 \mathrm{~Hz}$ & $250-500 \mathrm{~ms}$ & 7 & -72 & 40 & 0.231 & 0.141 & 0.071 & 0.037 & 4.19 & 0.0107 & Right cuneus & Brodmann area 7 \\
\hline & -56 & 55 & $100-150 \mathrm{~Hz}$ & $500-750 \mathrm{~ms}$ & 47 & -47 & -30 & 0.121 & 0.046 & 0.066 & 0.014 & 4.02 & 0.0264 & Right culmen & $\begin{array}{c}\text { Anterior } \\
\text { cerebellar lobe }\end{array}$ \\
\hline \multirow{3}{*}{ (Lef } & & & & & 12 & -87 & 10 & 0.134 & 0.047 & 0.069 & 0.024 & 5.49 & 0.0007 & Right cuneus & Brodmann area 17 \\
\hline & $\mathrm{ft}$ prec & neus) & $100-150 \mathrm{~Hz}$ & $750-1000 \mathrm{~ms}$ & 12 & -27 & 25 & 0.182 & 0.097 & 0.082 & 0.029 & 4.22 & 0.0115 & $\begin{array}{l}\text { Right posterior } \\
\text { cingulate }\end{array}$ & Brodmann area 23 \\
\hline & & & & & -8 & 3 & 0 & 0.150 & 0.075 & 0.066 & 0.022 & 4.11 & 0.0149 & Right caudate & $\begin{array}{l}\text { Head of caudate } \\
\text { nucleus }\end{array}$ \\
\hline
\end{tabular}

IC between seeds and targets showed significant differences between patients and controls during the auditory oddball task. BrainMap GingerALE Version 2.1 software was used to transform from MNI coordinates to the Talairach coordinate system and from Talairach coordinates to Brodmann areas. The Talairach software was created and developed by Jack Lancaster and Peter Fox at the Research Imaging Institute of the University of Texas Health Science Center San Antonio (UTHSCSA).

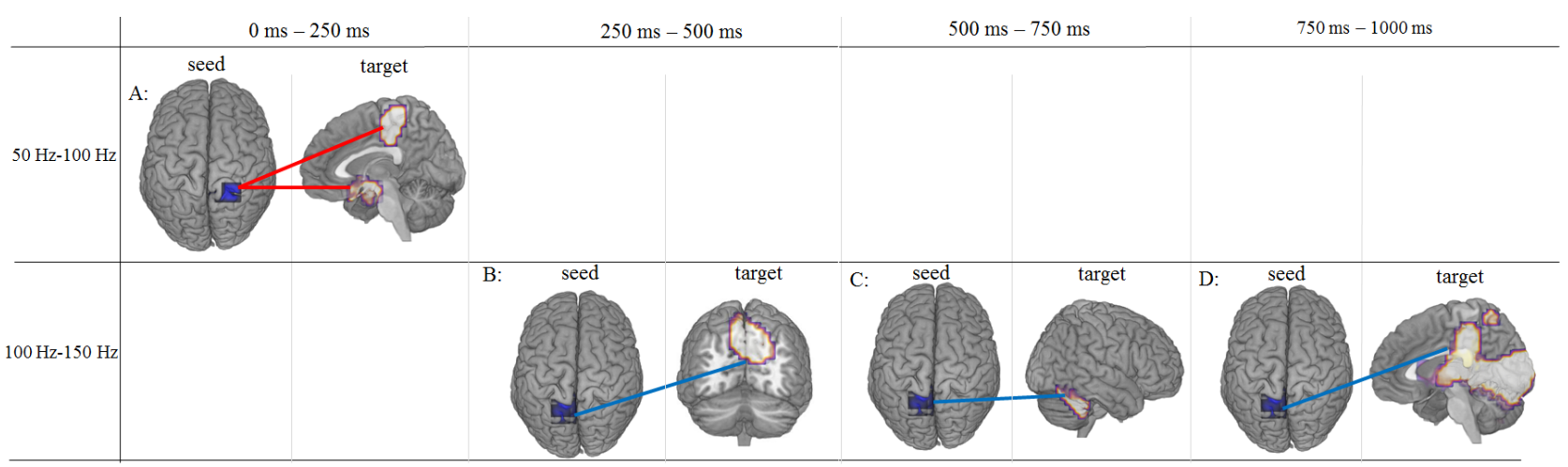

- Connectivity: IC decrease (Patient $<$ Control)

- Connectivity: IC increase (Patient $>$ Control)

Figure 2. IC between seeds and targets showing significant differences in patients with schizophrenia during the auditory oddball task compared to control subjects. A: IC between right precuneus and right paracentral lobule and between right precuneus and right hypothalamus was decreased in gamma band $(50-100 \mathrm{~Hz})$ at $0-250 \mathrm{~ms}$. B: IC between left precuneus and right precuneus was increased in gamma band $(100-150 \mathrm{~Hz})$ at $250-500 \mathrm{~ms}$. C: IC between left precuneus and right culmen was increased in gamma band $(100-150 \mathrm{~Hz})$ at $500-750 \mathrm{~ms}$. D: IC between left precuneus and a large area including cuneus, posterior cingulate and caudate regions in right hemisphere was increased in gamma band $(100-150 \mathrm{~Hz})$ at $750-1000 \mathrm{~ms} . \mathrm{p}<0.05$ (FWE).

in-network disconnection in the right hemisphere and between-network connectivity across both hemispheres. In the right hemisphere, IC in the high gamma band (50 $100 \mathrm{~Hz}$ ) was decreased between the precuneus and paracentral lobule and between the precuneus and hypothalamus within the time window of $0-250 \mathrm{~ms}$. On the other hand, IC in the high gamma band $(100-150 \mathrm{~Hz})$ showed inter-hemispheric dysfunction, which was increased between the left precuneus and right cuneus (Brodmann area 7) at $250-500 \mathrm{~ms}$, and between the left precuneus and right culmen at 500 - $750 \mathrm{~ms}$. At 750 $1000 \mathrm{~ms}$, IC was increased between the left precuneus and right cuneus (Brodmann area 17), between the left precuneus and right PCC, and between the left precuneus and the right head of the caudate nucleus. These results suggested that the correlation between the two hemispheres and parietal lobe, including the right and left precuneus, play principal roles in functional connectivity dysfunction in female schizophrenia.

\subsection{Precuneus}

In the study of ERD and ERS power, female schizophrenia patients showed decreased low gamma $(30-50 \mathrm{~Hz})$ band ERS power in the left precuneus (Brodmann area 7) at $500-750 \mathrm{~ms}$, and in the right precuneus (Brodmann area 7) at 750 - $1000 \mathrm{~ms}$ during the conventional oddball task (Figure 1, Table 2). These findings suggested decreased ERS power in the low gamma band in the right and left precuneus, but with differences in reaction times. 


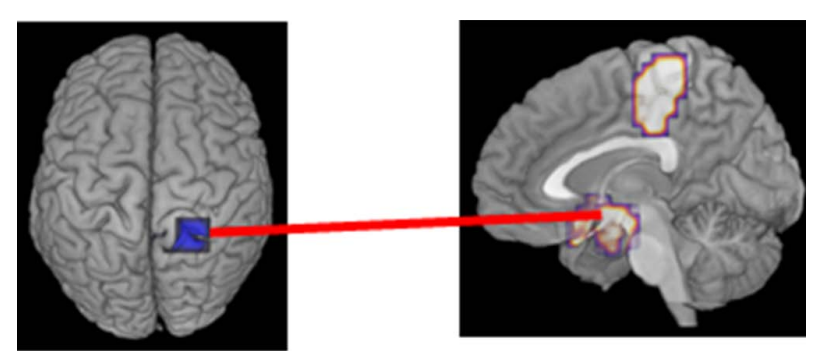

(a)

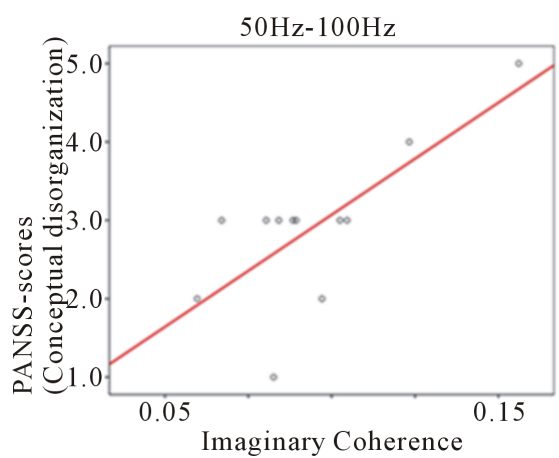

(b)

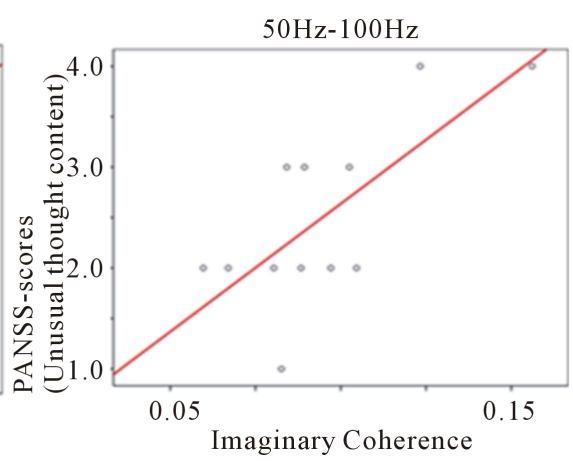

(c)

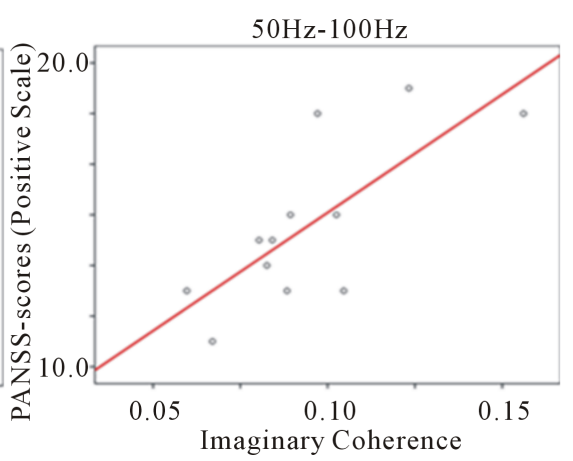

(d)

Figure 3. Correlation between IC and PANSS scores in high gamma band $(50-100 \mathrm{~Hz})$ at $0-250 \mathrm{~ms}$ during the auditory oddball task. (a) IC between right precuneus and right hypothalamus areas was significantly decreased compared to control subjects; (b) Significant positive correlation between IC and conceptual disorganization in PANSS scores $(r=0.746, p=0.005)$; (c) Significant positive correlation between IC and unusual thought content in PANSS scores $(r=0.746, p=0.005)$; (d) Significant positive correlation between IC and positive symptoms scale in PANSS $(r=0.728, p=0.007)$. Abbreviation: IC: imaginary coherence.

These findings were characteristic of female schizophrenia patients. Gamma ERS has been implicated in the coordination of activity between distributed neuronal assemblies in the service of sensory registration of stimuli and perceptual binding of their features, and schizophrenia patients have demonstrated deficits in the magnitude and/or phase synchrony of stimulus-evoked gamma oscillations [53]. Gamma ERS during sentence-level language comprehension has previously been linked with semantic unification, and increased gamma power was related to the predictability of an upcoming word based on the preceding sentence context [54]. Gamma ERS was associated with cortical activation while imagining the movement of body parts, and appeared to be located near somatosensory and motor areas [55]. The decreased ERS observed in the present study may be related to dysfunction in imagining the movement of body parts and sentence-level language comprehension in schizophrenia. The precuneus was functionally divided into three regions: the anterior, central, and posterior precuneus. The anterior precuneus was functionally connected with the superior parietal cortex, paracentral lobule, and motor cortex. The central precuneus was functionally connected to the dorsolateral prefrontal, dorsomedial prefrontal, and multimodal lateral inferior parietal cortex. The posterior precuneus was functionally connected to the adjacent visual cortical regions. These functional connectivities were differentiated from the more ventral networks associated with the posterior cingulate, which is connected with limbic structures [56]. Posterior parietal cortex function has been observed to influence space-based attention and motor intention, and to have prominent response properties associated with memory, which may arise through interactions with medial temporal cortex [57]. Schizophrenia patients showed significantly reduced activation in the gamma frequency band in the posterior region of the medial parietal cortex during an eyes-closed resting state in an MEG study [58]. Patients in another study showed differences in the precuneus and superior parietal, including hippocampus, parahippocampus, thalamus, and midbrain regions in the gamma band during standard pattern reversal stimulation, compared to control subjects [59]. Disturbances in self-referential and self-other discriminative processing were identified as a symptom in schizophrenia, and were related to the widely distributed neural fronto-temporal-parietal cortical network [60]. Recent developments in functional connectivity MRI (fcMRI) showed reduced functional connectivity to the parietal lobe, posterior cingulate cortex, thalamus, and striatum, and dysfunction in the frontoparietal network for various tasks requiring executive control in schizophrenia [61,62]. In our study, dysfunction in IC between the precuneus bilaterally and other regions sug- 
gested dysfunction in complicated functional connectivity in large scale networks in schizophrenia.

\subsection{Hypothalamus}

IC between the right precuneus and right hypothalamus was also decreased in the gamma band $(50-100 \mathrm{~Hz})$ at 0 - $250 \mathrm{~ms}$, and showed a significant positive correlation with conceptual disorganization, unusual thought content, and the positive symptoms scale in PANSS. Hypothalamic abnormalities in schizophrenia were associated with endocrine dysfunction the stress response and the hypothalamic-pituitary-adrenal (HPA) axis [54]. Patients with schizophrenia spectrum had a larger pituitary volume (larger in female than male patients), reflecting hyperactivity of the HPA axis, which may be related to a common vulnerability to stress in patients [63]. Dysregulation of HPA axis activity can be detected not only in depressed but also in schizophrenic patients [64,65], and the hypothesis of HPA axis hyperactivity in schizophrenia was supported by an experiment using a neurodevelopmental model of schizophrenia in rats [66]. HPA axis activity is associated with the severity of multiple types of symptoms in first-episode psychosis, and patients' diagnosis and clinical phase partially influence these associations [67]. Tognin et al. reported abnormally increased sizes of the hypothalamus and the mammillary bodies in schizophrenia, and that mammillary body volumes were associated with negative symptoms and anxiety, suggesting that the mammillary bodies with respect to the levels of related hormones may have an important role in modulating HPA axis in schizophrenia [68].

Our ability to interpret the present findings of decreased IC between the right precuneus and right hypothalamus in the high gamma band $(50-100 \mathrm{~Hz})$ within the $0-250 \mathrm{~ms}$ time window, and the significant positive correlations with conceptual disorganization and unusual thought content, are limited by the observational nature of our data. It is difficult to identify whether differences are due to schizophrenia proper or secondarily caused by reactions to psychiatric symptoms.

\subsection{Cerebellum}

In the high gamma band $(100-150 \mathrm{~Hz})$, IC was increased in patients compared to control females, including IC between the left precuneus and right cuneus (Brodmann area 7) at $250-500 \mathrm{~ms}$, IC between the left precuneus and right culmen at $500-750 \mathrm{~ms}$, and IC between the left precuneus and right cuneus (Brodmann area 17). Findings from studies in schizophrenia patients support the role of cerebellar impairment [69]. Neuropathological and neuroimaging studies linked cerebellar abnormalities with the widespread neuropsychological deficits in schizophrenia [70], and the cerebellum plays a key role in the cognitive dysmetria hypothesis of schizophrenia [71]. A disruption in the cortical-thalamiccerebellar-cortical circuit (CCTCC) leads to impairment in synchrony, or the smooth coordination of mental processes, and produces a diversity of symptoms. Though structural connectivity was impaired in the cerebellum, it was not local to any particular tract but appeared to have a wider, possibly global, distribution [72]. The neocerebellum is reported to play an important role in emotion, language, working memory, and executive functions [73], and focal cerebellar lesions caus cognitive and affective impairments [74,75]. A functional MRI (fMRI) study showed that the neocerebellum, particularly crus I and II, made contributions to parallel cortico-cerebellar loops involved in executive control, salience detection, and episodic memory/self-reflection, and the largest portions of the neocerebellum took part in the executive control network implicated in higher cognitive functions such as working memory [76].

Schizophrenia patients showed impaired functional connectivity between the cerebellum and several leftsided cerebral regions, including the hippocampus, thalamus, middle cingulate gyrus, triangular part of the inferior frontal gyrus, supplementary motor area, and lingual gyrus in two fMRI studies [77,78]. Neural disruption in the superior cerebellar peduncle was found in patients with schizophrenia in a diffusion tensor imaging (DTI) study [79], which may be involved in the cognitive abnormalities in schizophrenia. The bilateral cerebellum showed reduced functional connectivity to some regions, such as bilateral middle cingulate cortex and right paracentral lobule including left middle temporal gyrus, right thalamus, and bilateral cerebellum in schizophrenia patients in an fMRI and DTI study [78]. Another fMRI study showed that cerebellar-thalamic disconnections were the most prominent and were common to all cognitive-related networks, whereas cortico-cerebellar connectivity involved both an increase and decrease in functional connectivity, and depended more on the nature of the specific network [80]. These reports suggested that the functional disconnection and damaged anatomical connectivity between the cerebellum and other regions was related to dysfunction in schizophrenia. This functional disconnection may be related to disruption in the CCTCC, which may lead to impairment in synchrony and may cause cognitive dysmetria, and the impairment in this basic cognitive process defines the phenotype of schizophrenia and produces its diversity of symptoms [71]. Increased IC between the left precuneus and right cerebellar regions in female schizophrenia patients may be involved in disruption in the CCTCC.

\subsection{Posterior Cingulate Area in the Right Hemisphere}

IC between the left precuneus and right PCC was in- 
creased in the gamma band $(100-150 \mathrm{~Hz})$ at $750-1000$ $\mathrm{ms}$. The PCC has dense connectivity with the precuneus through the supramarginal gyrus, and the frontal pole through the caudal anterior cingulate cortex in the large-scale structural brain networks [81]. The PCC is a central part of the structural core of the brain as well as part of the default mode network, and plays a role in modulating the dynamic interaction between the cognitive control network and default mode networks [82]. That the PCC mediates exteroceptive vigilance is consistent with the idea that the PCC is part of the default network of brain areas associated with control of task engagement [83]. Bilateral PCC, including bilateral medial cingulate cortex, bilateral parahippocampal gyrus, left angular gyrus, left supramarginal gyrus, left lateral precuneus, and left occipital cortex, has been reported to show indistinguishable activity during future and past tasks [84]. Momentary lapses in attention that frequently impair goal-directed behavior were related to a failure to maintain deactivation during externally directed tasks, and longer reaction times were associated with increased target related activity in several regions of the defaultmode network, including the PCC, the precuneus, and the middle temporal gyrus [85]. The selective vulnerability of the posterior cingulate and precuneus has been suggested in diverse conditions, such as carbon monoxide poisoning, diffuse brain ischemia, Alzheimer disease, and pharmacologically induced animal models of schizophrenia [86]. Disconnection between the right PCC and the left precuneus may be related to vulnerability in these regions, and to dysfunction in the dynamic interaction between the cognitive control network and default mode networks in schizophrenia.

\subsection{Caudate Regions in the Right Hemisphere}

IC between the left precuneus and right caudate regions was increased in the gamma band $(100-150 \mathrm{~Hz})$ at 750 $1000 \mathrm{~ms}$. In an fMRI study during use of working memory, schizophrenia patients showed a critical dysfunction in cortico-striatal connectivity, underpinning information retrieval, and positive performance-related cortico-striatal functional connectivity between the right caudate and the right dorsolateral prefrontal cortices was absent [87]. Schizophrenia patients showed smaller clusters of greater amplitude of low-frequency fluctuations in the caudate, including the frontal, temporal/insular regions, putamen, and hippocampus, in an fMRI study in a resting state [88]. A regional homogeneity (ReHo) method combined with resting-state fMRI showed that ReHo abnormalities in schizophrenia were frequency-dependent in the inferior occipital gyrus and caudate body, suggesting abnormality in brain oscillation [89]. These findings suggested that dysfunction in the caudate nucleus is involved in cortico-striatal functional connectivity.

\section{CONCLUSIONS}

In conclusion, decreased and increased IC in the high gamma band $(50-100 \mathrm{~Hz}$ or/and $100-150 \mathrm{~Hz}$ ) within a particular time window reflect disturbances in brain dynamics in large-scale coordination in the brain of female schizophrenia patients during the auditory oddball task. The neural connectivity dysfunction was interpreted by the disconnection hypothesis of schizophrenia proposed by Friston [90,91]. Friston presented the functional architecture in hierarchical terms, based on (bidirectional) coupling, such as visual cortex, superior temporal sulcus, prefrontal cortex, PCC, posterior parietal cortex, angular gyrus, and frontal eye fields [92]. In the present study, the posterior parietal region (right and left precuneus) played a principal role in connectivity dysfunction of the functional architecture. In addition, this connectivity dysfunction was related to 3 gamma band oscillations $(30-50 \mathrm{~Hz}, 50-100 \mathrm{~Hz}$ and $100-150 \mathrm{~Hz})$ and 4 time windows $(0-250 \mathrm{~ms}, 250-500 \mathrm{~ms}, 500-750 \mathrm{~ms}$ and $750-1000 \mathrm{~ms}$ ), suggesting that temporal factors played an important role in the connectivity dysfunction. Therefore, in the investigation of functional disconnection, it is necessary to consider not only space but also time. In particular, IC between two seeds (right and left precuneus) and any targets in the brain was associated with both temporal and spatial parameters. IC between the right precuneus and right hypothalamus in the high gamma band $(50-100 \mathrm{~Hz})$ at $0-250 \mathrm{~ms}$ showed positive correlations with conceptual disorganization, unusual thought content, and positive symptoms scale in PANSS. This suggested neural connectivity dysfunction in the high gamma band associated with clinical symptoms of female schizophrenia.

However, we only examined IC between two seeds (right and left precuneus) and targets in other regions, and did not examine seeds other than the right and left precuneus. Further investigation of IC between other seeds and targets may show another IC dysfunction. In addition, all patients were treated with neuroleptics, which may have affected the present results. Altered coherences in the gamma band may be related not only to the pathophysiology of schizophrenia in female patients but also to effects of medication. In addition, it was unclear whether these changes are primary or secondary, and whether there are network-specific disconnections or dysfunction in multiple networks in schizophrenia. Although this study does not have an answer to these complicated problems, our study demonstrated that dysfunction in coherence in the high gamma band within a particular time window plays an important role in the pathophysiology of schizophrenia in female patients. Multidimensional study of the gamma band is expected to open a new avenue for clarifying the relationship be- 
tween brain pathophysiology and schizophrenic symptomatology.

\section{REFERENCES}

[1] Fries, P. (2009) Neuronal gamma-band synchronization as a fundamental process in cortical computation. Annual review of Neuroscience, 32, 209-224.

http://dx.doi.org/10.1146/annurev.neuro.051508.135603

[2] Uhlhaas, P.J. and Singer, W. (2012) Neuronal dynamics and neuropsychiatric disorders: Toward a translational paradigm for dysfunctional large-scale networks. Neuron, 75, 963-980. http://dx.doi.org/10.1016/j.neuron.2012.09.004

[3] Gray, C.M., König, P., Engel, A.K. and Singer, W. (1989) Oscillatory responses in cat visual cortex exhibit intercolumnar synchronization which reflects global stimulus properties. Nature, 338, 334-337.

http://dx.doi.org/10.1038/338334a0

[4] Gray, C.M. and McCormick, D.A. (1996) Chattering cells: Superficial pyramidal neurons contributing to the generation of synchronous oscillations in the visual cortex. Science, 274, 109-113.

http://dx.doi.org/10.1126/science.274.5284.109

[5] Pesaran, B., Pezaris, J.S., Sahani, M., Mitra, P.P. and Andersen, R.A. (2002) Temporal structure in neuronal activity during working memory in macaque parietal cortex. Nature Neuroscience, 5, 805-811.

http://dx.doi.org/10.1038/nn890

[6] Fries, P., Neuenschwander, S., Engel, A.K., Goebel, R. and Singer, W. (2001a) Rapid feature selective neuronal synchronization through correlated latency shifting. $\mathrm{Na}$ ture Neuroscience, 4, 194-200. http://dx.doi.org/10.1038/84032

[7] Fries, P., Reynolds, J.H., Rorie, A.E. and Desimone, R. (2001b) Modulation of oscillatory neuronal synchronization by selective visual attention. Science, 291, 15601563. http://dx.doi.org/10.1126/science. 1055465

[8] Grützner, C., Uhlhaas, P.J., Genc, E., Kohler, A., Singer, W. and Wibral, M. (2010) Neuroelectromagnetic correlates of perceptual closure processes. The Journal of Neuroscience, 30, 8342-8352. http://dx.doi.org/10.1523/JNEUROSCI.5434-09.2010

[9] Siegel, M., Donner, T.H., Oostenveld, R., Fries, P. and Engel, A.K. (2008) Neuronal synchronization along the dorsal visual pathway reflects the focus of spatial attention. Neuron, 60, 709-719. http://dx.doi.org/10.1016/j.neuron.2008.09.010

[10] Wyart, V. and Tallon-Baudry, C. (2008) Neural dissociation between visual awareness and spatial attention. The Journal of Neuroscience, 28, 2667-2679. http://dx.doi.org/10.1523/JNEUROSCI.4748-07.2008

[11] Kaiser, J., Heidegger, T., Wibral, M., Altmann, C.F. and Lutzenberger, W. (2008) Distinct gamma-band components reflect the short-term memory maintenance of different sound lateralization angles. Cerebral Cortex, 18, 2286-2295. http://dx.doi.org/10.1093/cercor/bhm251

[12] Vidal, J.R., Chaumon, M., O’Regan, J.K. and Tal-
lon-Baudry, C. (2006) Visual grouping and the focusing of attention induce gamma-band oscillations at different frequencies in human magnetoencephalogram signals. Journal of Cognitive Neuroscience, 18, 1850-1862. http://dx.doi.org/10.1162/jocn.2006.18.11.1850

[13] Womelsdorf, T., Schoffelen, J.M., Oostenveld, R., Singer, W., Desimone, R., Engel, A.K. and Fries, P. (2007) Modulation of neuronal interactions through neuronal synchronization. Science, 316, 1609-1612.

http://dx.doi.org/10.1126/science.1139597

[14] Buzsáki, G. and Silva, F.L. (2012) High frequency oscillations in the intact brain. Progress in Neurobiology, 98, 241-249.

http://dx.doi.org/10.1016/j.pneurobio.2012.02.004

[15] Uhlhaas, P.J., Pipa, G., Lima, B., Melloni, L., Neuenschwander, S., Nikolić, D. and Singer, W. (2009) Neural synchrony in cortical networks: History, concept and current status. Frontiers in Integrative Neuroscience, 3, 17. http://dx.doi.org/10.3389/neuro.07.017.2009

[16] Spencer, K.M., Salisbury, D.F., Shenton, M.E. and McCarley, R.W. (2008) Gamma-band auditory steady-state responses are impaired in first episode psychosis. Biological Psychiatry, 64, 369-375. http://dx.doi.org/10.1016/j.biopsych.2008.02.021

[17] Kwon, J.S., O’Donnell, B.F., Wallenstein, G.V., Greene, R.W., Hirayasu, Y., Nestor, P.G., Hasselmo, M.E., Potts, G.F., Shenton, M.E. and McCarley, R.W. (1999) Gamma frequency-range abnormalities to auditory stimulation in schizophrenia. Archives of General Psychiatry, 56, 10011005. http://dx.doi.org/10.1001/archpsyc.56.11.1001

[18] Lee, K.H., Williams, L.M., Haig, A. and Gordon, E. (2003) "Gamma (40 Hz) phase synchronicity" and symptom dimensions in schizophrenia. Cognitive Neuropsychiatry, 8, 57-71. http://dx.doi.org/10.1080/713752240

[19] Slewa-Younan, S., Gordon, E., Harris, A.W., Haig, A.R., Brown, K.J., Flor-Henry, P. and Williams, L.M. (2004) Sex differences in functional connectivity in first-episode and chronic schizophrenia patients. The American Journal of Psychiatry, 161, 1595-1602. http://dx.doi.org/10.1176/appi.ajp.161.9.1595

[20] Symond, M.B., Harris, A.W., Gordon, E. and Williams, L.M. (2005) "Gamma synchrony" in first-episode schizophrenia: A disorder of temporal connectivity? The American Journal of Psychiatry, 162, 459-465. http://dx.doi.org/10.1176/appi.ajp.162.3.459

[21] Light, G.A., Hsu, J.L., Hsieh, M.H., Meyer-Gomes, K., Sprock, J., Swerdlow, N.R. and Braff, D.L. (2006) Gamma band oscillations reveal neural network cortical coherence dysfunction in schizophrenia patients. Biological Psychiatry, 60, 1231-1240. http://dx.doi.org/10.1016/j.biopsych.2006.03.055

[22] Uhlhaas, P.J. and Singer, W. (2006) Neural synchrony in brain disorders: Relevance for cognitive dysfunctions and pathophysiology. Neuron, 52, 155-168. http://dx.doi.org/10.1016/j.neuron.2006.09.020

[23] Uhlhaas, P.J., Haenschel, C., Nikolić, D. and Singer, W. (2008) The role of oscillations and synchrony in cortical networks and their putative relevance for the pathophysi- 
ology of schizophrenia. Schizophrenia Bulletin, 34, 927943. http://dx.doi.org/10.1093/schbul/sbn062

[24] Uhlhaas, P.J. and Singer, W. (2010a) Abnormal neural oscillations and synchrony in schizophrenia. Nature Reviews Neuroscience, 11, 100-113. http://dx.doi.org/10.1038/nrn2774

[25] Uhlhaas, P.J., Roux, F., Rodriguez, E., Rotarska-Jagiela, A. and Singer, W. (2010b) Neural synchrony and the development of cortical networks. Trends in Cognitive Sciences, 14, 72-80.

http://dx.doi.org/10.1016/j.tics.2009.12.002

[26] Spencer, K.M., Niznikiewicz, M.A., Nestor, P.G., Shenton, M.E. and McCarley, R.W. (2009) Left auditory cortex gamma synchronization and auditory hallucination symptoms in schizophrenia. BMC Neuroscience, 10, 85 . http://dx.doi.org/10.1186/1471-2202-10-85

[27] Uhlhaas, P.J., Pipa, G., Neuenschwander, S., Wibral, M. and Singer, W. (2011) A new look at gamma? High- $(>60$ $\mathrm{Hz}) \gamma$-band activity in cortical networks: Function, mechanisms and impairment. Progress in Biophysics and Molecular Biology, 105, 14-28. http://dx.doi.org/10.1016/j.pbiomolbio.2010.10.004

[28] Canolty, R.T., Edwards, E., Dalal, S.S., Soltani, M., Nagarajan, S.S., Kirsch, H.E., Berger, M.S., Barbaro, N.M. and Knight, R.T. (2006) High gamma power is phaselocked to theta oscillations in human neocortex. Science, 313, 1626-1628.

http://dx.doi.org/10.1126/science.1128115

[29] Canolty, R.T. and Knight, R.T. (2010) The functional role of cross-frequency coupling. Trends in Cognitive Sciences, 14, 506-515. http://dx.doi.org/10.1016/j.tics.2010.09.001

[30] Jensen, O. and Colgin, L.L. (2007) Cross-frequency coupling between neuronal oscillations. Trends in Cognitive Sciences, 11, 267-269. http://dx.doi.org/10.1016/i.tics.2007.05.003

[31] Palva, J.M., Palva, S. and Kaila, K. (2005) Phase synchrony among neuronal oscillations in the human cortex. The Journal of Neuroscience, 25, 3962-3972. http://dx.doi.org/10.1523/JNEUROSCI.4250-04.2005

[32] Fries, P. (2005) A mechanism for cognitive dynamics: Neuronal communication through neuronal coherence. Trends in Cognitive Sciences, 9, 474-480. http://dx.doi.org/10.1016/j.tics.2005.08.011

[33] Gray, C.M. and Viana, Di Prisco, G. (1997) Stimulusdependent neuronal oscillations and local synchronization in striate cortex of the alert cat. The Journal of Neuroscience, 17, 3239-3253.

[34] Walla, P., Hufnagl, B., Lindinger, G., Deecke, L. and Lang, W. (2001) Physiological evidence of gender differences in word recognition: A magnetoencephalographic (MEG) study. Cognitive Brain Research, 12, 49-54. http://dx.doi.org/10.1016/S0926-6410(01)00028-3

[35] Reite, M., Sheeder, J., Teale, P., Richardson, D., Adams, M. and Simon, J. (1995) MEG based brain laterality: Sex differences in normal adults. Neuropsychologia, 33, 16071616. http://dx.doi.org/10.1016/0028-3932(95)00112-3

[36] Jaušovec, N. and Jaušovec, K. (2009) Do women see things differently than men do? Neuroimage, 45, 198-207. http://dx.doi.org/10.1016/j.neuroimage.2008.11.013

[37] Slewa-Younan, S., Gordon, E., Williams, L., Haig, A.R. and Goldberg, E. (2001) Sex differences, gamma activity and schizophrenia. The International Journal of Neuroscience, 107, 131-144. http://dx.doi.org/10.3109/00207450109149762

[38] Fujimoto, T., Okumura, E., Takeuchi, K., Kodabashi, A., Otsubo, T., Nakamura, K., Kamiya, S., Higashi, Y., Yuji, T., Honda, K., Shimooki, S. and Tamura, T. (2013) Dysfunctional cortical connectivity during the auditory oddball task in patients with schizophrenia. The Open Neuroimaging Journal, 7, 15-26. http://dx.doi.org/10.2174/1874440001307010015

[39] Crone, N.E., Miglioretti, D.L., Gordon, B. and Lesser, R.P. (1998a) Functional mapping of human sensorimotor cortex with electrocorticographic spectral analysis. II. Event-related synchronization in the gamma band. Brain, 121, 2301-2315. http://dx.doi.org/10.1093/brain/121.12.2301

[40] Crone, N.E., Miglioretti, D.L., Gordon, B., Sieracki, J.M., Wilson, M.T., Uematsu, S. and Lesser, R.P. (1998b) Functional mapping of human sensorimotor cortex with electrocorticographic spectral analysis. I. Alpha and beta event-related desynchronization. Brain, 121, 2271-2299. http://dx.doi.org/10.1093/brain/121.12.2271

[41] Crone, N.E., Boatman, D., Gordon, B. and Hao, L. (2001a) Induced electrocorticographic gamma activity during auditory perception. Clinical Neurophysiology, 112, 565582. http://dx.doi.org/10.1016/S1388-2457(00)00545-9

[42] Crone, N.E., Hao, L., Hart Jr., J., Boatman, D., Lesser, R.P., Irizarry, R. and Gordon, B. (2001b) Electrocorticographic gamma activity during word production in spoken and sign language. Neurology, 57, 2045-2053. http://dx.doi.org/10.1212/WNL.57.11.2045

[43] Ohara, S., Ikeda, A., Kunieda, T., Yazawa, S., Baba, K., Nagamine, T., Taki, W., Hashimoto, N., Mihara, T. and Shibasaki, H. (2000) Movement-related change of electrocorticographic activity in human supplementary motor area proper. Brain, 123, 1203-1215. http://dx.doi.org/10.1093/brain/123.6.1203

[44] Pfurtscheller, G., Graimann, B., Huggins, J.E., Levine, S.P. and Schuh, L.A. (2003) Spatiotemporal patterns of beta desynchronization and gamma synchronization in corticographic data during self-paced movement. Clinical Neurophysiology, 114, 1226-1236. http://dx.doi.org/10.1016/S1388-2457(03)00067-1

[45] Crone, N.E., Sinai, A. and Korzeniewska, A. (2006) Highfrequency gamma oscillations and human brain mapping with electrocorticography. Progress in Brain Research, 159, 275-295. http://dx.doi.org/10.1016/S0079-6123(06)59019-3

[46] Kay, S.R., Fiszbein, A. and Opler, L.A. (1987) The positive and negative syndrome scale (PANSS) for schizophrenia. Schizophrenia Bulletin, 13, 261-276. http://dx.doi.org/10.1093/schbul/13.2.261

[47] Robinson, S.E. and Vrba, J. (1999) Functional neuroimaging by synthetic aperture magnetometry (SAM). In: T. Yoshimoto, M. Kotani, S. Kuriki, H. Karibe and N. Nakasato, Eds., Recent Advances in Biomagnetism, Tohoku 
University Press, Sendai, 302-305.

[48] Sekihara, K., Nagarajan, S.S., Poeppel, D. and Marantz, A. (2004) Asymptotic SNR of scalar and vector minimum-variance beamformers for neuromagnetic source reconstruction. IEEE Transactions on Bio-Medical Engineering, 51, 1726-1734.

http://dx.doi.org/10.1109/TBME.2004.827926

[49] Sekihara, K., Hild, K.E., Dalal, S.S. and Nagarajan, S.S. (2008) Performance of prewhitening beamforming in MEG dual experimental conditions. IEEE Transactions on Bio-Medical Engineering, 55, 1112-1121. http://dx.doi.org/10.1109/TBME.2008.915726

[50] Dalal, S.S., Guggisberg, A.G., Edwards, E., Sekihara, K., Findlay, A.M., Canolty, R.T., Berger, M.S., Knight, R.T., Barbaro, N.M., Kirsch, H.E. and Nagarajan, S.S. (2008) Five-dimensional neuroimaging: Localization of the time-frequency dynamics of cortical activity. Neuroimage, 40, 1686-1700.

http://dx.doi.org/10.1016/j.neuroimage.2008.01.023

[51] Nolte, G., Bai, O., Wheaton, L., Mari, Z., Vorbach, S. and Hallett, M. (2004) Identifying true brain interaction from EEG data using the imaginary part of coherency. Clinical Neurophysiology, 115, 2292-2307. http://dx.doi.org/10.1016/j.clinph.2004.04.029

[52] Sekihara, K., Owen, J.P., Trisno, S. and Nagarajan, S.S. (2011) Removal of spurious coherence in MEG sourcespace coherence analysis. IEEE Transactions on BioMedical Engineering, 58, 3121-3129. http://dx.doi.org/10.1109/TBME.2011.2162514

[53] Perez, V.B., Roach, B.J., Woods, S.W., Srihari, V.H., McGlashan, T.H., Ford, J.M. and Mathalon, D.H. (2013) Early auditory gamma-band responses in patients at clinical high risk for schizophrenia. Supplements to Clinical Neurophysiology, 62, 147-162. http://dx.doi.org/10.1016/B978-0-7020-5307-8.00010-7

[54] Wang, L., Zhu, Z. and Bastiaansen, M. (2012) Integration or predictability? A further specification of the functional role of gamma oscillations in language comprehension. Frontiers in Psychology, 3, 187. http://dx.doi.org/10.3389/fpsyg.2012.00187

[55] Matsunaga, T., Katayama, Y., Hayami, T. and Iramina, K. (2008) Measurements of the micro/beta ERD and gamma ERS during the imagination of body parts movement. Conference Proceedings - IEEE Engineering in Medicine and Biology Society, 2008, 4130-4133. http://dx.doi.org/10.1109/IEMBS.2008.4650118

[56] Margulies, D.S., Vincent, J.L., Kelly, C., Lohmann, G., Uddin, L.Q., Biswal, B.B., Villringer, A., Castellanos, F.X., Milham, M.P. and Petrides, M. (2009) Precuneus shares intrinsic functional architecture in humans and monkeys. Proceedings of the National Academy of Sciences of the United States of America, 106, 20069-20074. http://dx.doi.org/10.1073/pnas.0905314106

[57] Shannon, B.J. and Buckner, R.L. (2004) Functional-anatomic correlates of memory retrieval that suggest nontraditional processing roles for multiple distinct regions within posterior parietal cortex. The International Journal of Neuroscience, 24, 10084-10092. http://dx.doi.org/10.1523/JNEUROSCI.2625-04.2004
[58] Rutter, L., Carver, F.W., Holroyd, T., Nadar, S.R., Mitchell-Francis, J., Apud, J., Weinberger, D.R. and Coppola, R. (2009) Magnetoencephalographic gamma power reduction in patients with schizophrenia during resting condition. Human Brain Mapping, 30, 3254-3264. http://dx.doi.org/10.1002/hbm.20746

[59] González-Hernández, J.A., Pita-Alcorta, C., Castañeda, H., Trujillo-Barreto, N. and Scherbaum, W.A. (2009) BET differences among simultaneous evoked frequency band responses during early-stage visual processing distinguish schizophrenia from healthy subjects. Neuroscience Letters, 450, 7-11.

http://dx.doi.org/10.1016/j.neulet.2008.10.109

[60] Brent, B.K., Seidman, L.J., Thermenos, H.W., Holt, D.J. and Keshavan, M.S. (2013) Self-disturbances as a possible premorbid indicator of schizophrenia risk: A neurodevelopmental perspective. Schizophrenia Research, in press. http://dx.doi.org/10.1016/j.schres.2013.07.038

[61] Zhou, Y., Liang, M., Tian, L., Wang, K., Hao, Y., Liu, H., Liu, Z. and Jiang, T. (2007) Functional disintegration in paranoid schizophrenia using resting-state fMRI. Schizophrenia Research, 97, 194-205. http://dx.doi.org/10.1016/j.schres.2007.05.029

[62] Tu, P.C., Lee, Y.C., Chen, Y.S., Li, C.T. and Su, T.P. (2013) Schizophrenia and the brain's control network: Aberrant within- and between-network connectivity of the frontoparietal network in schizophrenia. Schizophrenia Research, 147, 339-347. http://dx.doi.org/10.1016/j.schres.2013.04.011

[63] Takahashi, T., Suzuki, M., Velakoulis, D., Lorenzetti, V., Soulsby, B., Zhou, S.Y., Nakamura, K., Seto, H., Kurachi, M. and Pantelis, C. (2009) Increased pituitary volume in schizophrenia spectrum disorders. Schizophrenia Research, 108, 114-121.

http://dx.doi.org/10.1016/j.schres.2008.12.016

[64] Szymańska, M., Budziszewska, B., Jaworska-Feil, L., Basta-Kaim, A., Kubera, M., Leśkiewicz, M., Regulska, M. and Lasoń, W. (2009a) The effect of antidepressant drugs on the HPA axis activity, glucocorticoid receptor level and FKBP51 concentration in prenatally stressed rats. Psychoneuroendocrinology, 34, 822-832. http://dx.doi.org/10.1016/j.psyneuen.2008.12.012

[65] Szymańska, M., Suska, A., Budziszewska, B., JaworskaFeil, L., Basta-Kaim, A., Leśkiewicz, M., Kubera, M., Gergont, A., Kroczka, S., Kaciński, M. and Lasoń, W. (2009b) Prenatal stress decreases glycogen synthase kinase-3 phosphorylation in the rat frontal cortex. Pharmacological Reports, 61, 612-620.

[66] Basta-Kaim, A., Budziszewska, B., Leśkiewicz, M., Fijał, K., Regulska, M., Kubera, M., Wędzony, K. and Lasoń, W. (2011) Hyperactivity of the hypothalamus-pituitaryadrenal axis in lipopolysaccharide-induced neurodevelopmental model of schizophrenia in rats: Effects of antipsychotic drugs. European Journal of Pharmacology, 650, 586-595. http://dx.doi.org/10.1016/j.ejphar.2010.09.083

[67] Belvederi Murri, M., Pariante, C.M., Dazzan, P., Hepgul, N., Papadopoulos, A.S., Zunszain, P., Di Forti, M., Murray, R.M. and Mondelli. V. (2012) Hypothalamic-pitui- 
tary-adrenal axis and clinical symptoms in first-episode psychosis. Psychoneuroendocrinology, 37, 629-644. http://dx.doi.org/10.1016/j.psyneuen.2011.08.013

[68] Tognin, S., Rambaldelli, G., Perlini, C., Bellani, M., Marinelli, V., Zoccatelli, G., Alessandrini, F., Pizzini, F.B., Beltramello, A., Terlevic, R., Tansella, M., Balestrieri, M. and Brambilla, P. (2012) Enlarged hypothalamic volumes in schizophrenia. Psychiatry Research, 204, 75-81. http://dx.doi.org/10.1016/i.pscychresns.2012.10.006

[69] Picard, H., Amado, I., Mouchet-Mages, S., Olié, J.P. and Krebs, M.O. (2008) The role of the cerebellum in schizophrenia: An update of clinical, cognitive, and functional evidences. Schizophrenia bulletin, 34, 155-172. http://dx.doi.org/10.1093/schbul/sbm049

[70] Katsetos, C.D., Hyde, T.M. and Herman, M.M. (1997) Neuropathology of the cerebellum in schizophrenia-An update: 1996 and future directions. Biological Psychiatry, 42, 213-224. http://dx.doi.org/10.1016/S0006-3223(96)00313-7

[71] Andreasen, N.C., Nopoulos, P., O'Leary, D.S., Miller, D.D., Wassink, T. and Flaum, M. (1999) Defining the phenotype of schizophrenia: Cognitive dysmetria and its neural mechanisms. Biological Psychiatry, 46, 908-920. http://dx.doi.org/10.1016/S0006-3223(99)00152-3

[72] Kanaan, R.A., Borgwardt, S., McGuire, P.K., Craig, M.C., Murphy, D.G., Picchioni, M., Shergill, S.S., Jones, D.K. and Catani, M. (2009) Microstructural organization of cerebellar tracts in schizophrenia. Biological Psychiatry, 66, 1067-1069.

http://dx.doi.org/10.1016/j.biopsych.2009.07.028

[73] Stoodley, C.J. and Schmahmann, J.D. (2009) Functional topography in the human cerebellum: A meta-analysis of neuroimaging studies. Neuroimage, 44, 489-501. http://dx.doi.org/10.1016/j.neuroimage.2008.08.039

[74] Schmahmann, J.D. and Sherman, J.C. (1998) The cerebellar cognitive affective syndrome. Brain, 121, 561-579. http://dx.doi.org/10.1093/brain/121.4.561

[75] Levisohn, L., Cronin-Golomb, A. and Schmahmann, J.D. (2000) Neuropsychological consequences of cerebellar tumour resection in children: Cerebellar cognitive affective syndrome in a paediatric population. Brain, 123, 1041-1050. http://dx.doi.org/10.1093/brain/123.5.1041

[76] Habas, C., Kamdar, N., Nguyen, D., Prater, K., Beckmann, C.F., Menon, V. and Greicius, M.D. (2009) Distinct cerebellar contributions to intrinsic connectivity networks. The International Journal of Neuroscience, 29, 8586-8594.

http://dx.doi.org/10.1523/JNEUROSCI.1868-09.2009

[77] Collin, G., Hulshoff Pol, H.E., Haijma, S.V., Cahn, W., Kahn, R.S. and van den Heuvel, M.P. (2011) Impaired cerebellar functional connectivity in schizophrenia patients and their healthy siblings. Frontiers in Psychiatry, 2, 73. http://dx.doi.org/10.3389/fpsyt.2011.00073

[78] Liu, H., Fan, G., Xu, K. and Wang, F. (2011) Changes in cerebellar functional connectivity and anatomical connectivity in schizophrenia: A combined resting-state functional MRI and diffusion tensor imaging study. Journal of Magnetic Resonance Imaging, 34, 1430-1438. http://dx.doi.org/10.1002/jmri.22784
[79] Okugawa, G., Nobuhara, K., Minami, T., Takase, K., Sugimoto, T., Saito, Y., Yoshimura, M. and Kinoshita, T. (2006) Neural disorganization in the superior cerebellar peduncle and cognitive abnormality in patients with schizophrenia: A diffusion tensor imaging study. Progress in Neuro-Psychopharmacology \& Biological Psychiatry, 30, 1408-1412.

http://dx.doi.org/10.1016/j.pnpbp.2006.05.014

[80] Chen, Y.L., Tu, P.C., Lee, Y.C., Chen, Y.S., Li, C.T. and Su, T.P. (2013) Resting-state fMRI mapping of cerebellar functional dysconnections involving multiple large-scale networks in patients with schizophrenia. Schizophrenia Research, 149, 26-34. http://dx.doi.org/10.1016/j.schres.2013.05.029

[81] Hagmann, P., Cammoun, L., Gigandet, X., Meuli, R., Honey, C.J., Wedeen, V.J. and Sporns, O. (2008) Mapping the structural core of human cerebral cortex. PLoS Biology, 6, e159. http://dx.doi.org/10.1371/journal.pbio.0060159

[82] Leech, R., Kamourieh, S., Beckmann, C.F. and Sharp, D.J. (2011) Fractionating the default mode network: Distinct contributions of the ventral and dorsal posterior cingulate cortex to cognitive control. The International Journal of Neuroscience, 31, 3217-3224. http://dx.doi.org/10.1523/JNEUROSCI.5626-10.2011

[83] Hayden, B.Y., Smith, D.V. and Platt, M.L. (2009) Electrophysiological correlates of default-mode processing in macaque posterior cingulate cortex. Proceedings of the National Academy of Sciences of the United States of America, 106, 5948-5953. http://dx.doi.org/10.1073/pnas.0812035106

[84] Szpunar, K.K., Watson, J.M. and McDermott, K.B. (2007) Neural substrates of envisioning the future. Proceedings of the National Academy of Sciences of the United States of America, 104, 642-647. http://dx.doi.org/10.1073/pnas.0610082104

[85] Weissman, D.H., Roberts, K.C., Visscher, K.M. and Woldorff, M.G. (2006) The neural bases of momentary lapses in attention. Nature Neuroscience, 9, 971-978. http://dx.doi.org/10.1038/nn1727

[86] Raichle, M.E., MacLeod, A.M., Snyder, A.Z., Powers, W.J., Gusnard, D.A. and Shulman, G.L. (2001) A default mode of brain function. Proceedings of the National Academy of Sciences of the United States of America, 98, 676-682. http://dx.doi.org/10.1073/pnas.98.2.676

[87] Quidé, Y., Morris, R.W., Shepherd, A.M., Rowland, J.E. and Green, M.J. (2013) Task-related fronto-striatal functional connectivity during working memory performance in schizophrenia. Schizophrenia Research, in press. http://dx.doi.org/10.1016/j.schres.2013.08.009

[88] Turner, J.A., Damaraju, E., van Erp, T.G., Mathalon, D.H., Ford, J.M., Voyvodic, J., Mueller, B.A., Belger, A., Bustillo, J., McEwen, S., Potkin, S.G., Fbirn and Calhoun, V.D. (2013) A multi-site resting state fMRI study on the amplitude of low frequency fluctuations in schizophrenia. Frontires in Neuroscience, 7, 137. http://dx.doi.org/10.3389/fnins.2013.00137

[89] Yu, R., Hsieh, M.H., Wang, H.L., Liu, C.M., Liu, C.C., Hwang, T.J., Chien, Y.L., Hwu, H.G. and Tseng, W.Y. 
(2013) Frequency dependent alterations in regional homogeneity of baseline brain activity in schizophrenia. PLoS One, 8, e57516.

http://dx.doi.org/10.1371/journal.pone.0057516

[90] Friston, K.J. (1998) The disconnection hypothesis. Schizophrenia Research, 30, 115-125.

http://dx.doi.org/10.1016/S0920-9964(97)00140-0
[91] Friston, K.J. (1999) Schizophrenia and the disconnection hypothesis. Acta Psychiatrica Scandinavica Supplementum, 395, 68-79.

http://dx.doi.org/10.1111/j.1600-0447.1999.tb05985.x

[92] Friston, K.J. (2011) Functional and effective connectivity: A review. Brain Connectivity, 1, 13-36. http://dx.doi.org/10.1089/brain.2011.0008. 